\title{
A FUZZY GROUP DECISION MAKING FOR A RAIL-ROAD TRANSSHIPMENT YARD MICRO LOCATON PROBLEM
}

\author{
Ivan Belošević1 ${ }^{*}$, Sanjin Milinković ${ }^{2}$, Peter Marton $^{3}$, Slavko Vesković ${ }^{4}$ and Miloš Ivić ${ }^{5}$ \\ 1,2, 4,5 University of Belgrade, Faculty of Transport Traffic and Engineering, Serbia \\ ${ }^{3}$ University of Žilina, Faculty of Management Science and Informatics, Slovakia
}

\begin{abstract}
Rail-road transhipment yards serve as interchange points between rail and road providing transhipment of loading units. These yards are of great importance for smooth functioning not only of railways but also of the whole intermodal transportation chains. The problem of choosing location of railway facilities, such as yards and depots, has great practical importance and is widely considered in the literature. In this paper, we present a multi criteria decision making (MCMD) model for selecting the most suitable micro location of a rail-road transhipment yard. The developed MCMD model is based on combining a compromise programming technique with the theory of fuzzy numbers. This approach was chosen to solve the considered location problem due to the specific decision-making environment that reflects in the presence of non-commensurable and conflicting criteria. As a case study we analysed several alternatives for locating rail-road transhipment facilities in the area of the rail freight yard in Vršac. The results confirm validity and usefulness of this approach.
\end{abstract}

\section{Introduction}

Rail-road combined transport refers to the movement of freight from an origin to a destination relying on railways and trucks. Railways performs long distance hauling supported by trucks that provide first/last mile transport. Complementing these two divergent transport modes, rail-road combined transport enables a sustainable modal share. From the aspect of sustainability, the main contributions of railways refer to high capacity's reserves, reliability and safety, reduction in energy consumption and pollution.

The high increase of container transportation emphasises the role of interchange points. Rail-road transhipment yards serve as interchange points between rail and road where loading units (such as containers, swap bodies or semi-trailers) change transportation mode. Wide range of decision problems arise in the area of managing transhipment yards hierarchically arranged at different planning levels. Decision problems referring micro location, layout design and operational process of a rail-road transhipment yard influence on the local infrastructure and organization of the yard itself. The final results of appropriate decisions on these problems reflect in the reduction of container transhipment costs. Decision problems in the aspect of layout design and operational process have been discussed in papers [1-2].

In contrast to the previous research, this paper considers the location problem of a rail-road transhipment yard. Selecting location is one of the complex problems and requires an extensive multicriteria evaluation process. The location of transhipment yards has to be considered carefully due to the impacts on different stakeholders involved in the

* Corresponding author: i.belosevic@sf.bg.ac.rs whole transportation chain. These impacts mainly refer to the financial, operational, economic, spatial and environmental aspects among investors, transhipment yard managers, freight and logistic operators, industry and the local community. Due to the such complex circumstances, we propose the multi-criteria decision making (MCDM) approach for solving transhipment yard location problem. We develop MCMD model based on combining a compromise programming technique with the theory of fuzzy numbers. This approach is chosen to solve the considered micro location problem due to the specific decision-making environment that reflects in the presence of noncommensurable and conflicting criteria. The model is based on linguistic variables and extends the evaluation problem to a Group Decision Making (GDM) procedure aggregating individual expert opinions. As a case study we analyse several alternatives for locating rail-road transhipment facilities in the area of the rail freight yard in Vršac. The results confirm validity and usefulness of this model that could serve as a tool for assisting decision makers in selecting the most suitable transhipment yard location.

The paper is structured as follows. Section 2 presents compromise programming approach using VIKOR method. Section 3 determines the proposed framework for selecting location of transhipment yard. The case study is provided in Section 4 and concluding remarks are summarized in Section 5. 


\section{VIKOR method: a compromise programming tool}

The program package VIKOR, based on compromise programming, has been developed by Opricović $[3,4]$ for the multicriteria ranking of alternative solutions. The use of VIKOR method for the evaluation of railway infrastructure alternatives was proposed in papers $[5,6]$.

The method focuses on the ranking and selection of alternatives in the presence of conflicting criteria. The ideal point is used as the reference point in the area covered by criterial functions. Commonly, there does not exist an alternative that meet all criteria at the same time. The solution closest to the ideal point is proposed for the compromise solution following the Lp metric adopted from compromise programming:

$$
\begin{aligned}
& L_{i}^{p}=\left\{\sum_{j=1}^{n}\left[\frac{w_{j}\left(f_{j}^{*}-f_{i j}\right)}{\left(f_{j}^{*}-f_{j}^{-}\right)}\right]^{p}\right\}^{1 / p} \\
& 1 \leq p \leq \infty, i=1, \ldots, m
\end{aligned}
$$

where $m$ is the number of feasible alternatives $A_{i}(i=$ $1, \ldots, m) ; f_{i j}$ is the value of the $j^{\text {th }}$ criterion function for alternative $A_{i} ; f_{j}^{*}$ and $f_{j}^{-}$are the best and the worst values of the $j^{\text {th }}$ criterion function, respectively; and $w_{j}(j=1, \ldots, n)$ are weighting coefficients (weights).

In the VIKOR method, $S_{i}$ and $R_{i}$ stand for boundary ranking measures (see Eq. 2 and Eq. 3). The measure $S_{i}$ presents the lower bound when $p$ takes value 1 in Eq. 1 , while the measure $R_{i}$ presents the upper bound when $p$ takes value $\infty$.

$S_{i}=\sum_{j=1}^{n} w_{j}\left(f_{j}^{*}-f_{i j}\right) /\left(f_{j}^{*}-f_{j}^{-}\right)$

$R_{i}=\max _{j}\left[w_{j}\left(f_{j}^{*}-f_{i j}\right) /\left(f_{j}^{*}-f_{j}^{-}\right)\right]$

The main compromise ranking measure $Q_{i}$ aggregates $S_{i}$ and $R_{i}$ providing a balance between these two divergent ranking measures:

$Q_{i}=\frac{v\left(S_{i}-S^{*}\right)}{\left(S^{-}-S^{*}\right)}+(1-v)\left(R_{i}-R^{*}\right) /\left(R^{-}-R^{*}\right)$

where $S^{-}=\max _{i} S_{i}, \quad S^{*}=\min _{i} S_{i}, \quad R^{-}=\max _{i} R_{i}$, $R^{*}=\min _{i} R_{i}$ and $v \in[0,1]$. The parameter $v$ is introduced as the weight of the decision-making strategy.

\section{The proposed model}

The proposed model evaluates alternatives applying VIKOR method extended with fuzzy set theory. The proposed method uses fuzzy sets in describing uncertainties for different criteria involved in the location problem. In this way, Fuzzy VIKOR method finds compromise solution which is closest to the ideal scheme under fuzzy environment. The proposed framework for ranking alternatives and selecting the most suitable micro location of a rail-road transhipment yard is presented in Figure 1.
The method is very simple for practical application and gives an opportunity for decision makers to test the stability of the final ranking results. The applied methodology assumes that experts determine the weights of criteria and evaluate alternatives using linguistic variables. Thereafter, linguistic variables are transformed into the fuzzy numbers to reduce the subjectivity and its impact on the evaluation.

The Fuzzy VIKOR method can be summarized as the following steps:

Step 1: Generate set of alternatives for the reconstruction of the observed railway line $A_{i}\left(A_{1}, A_{2}, \ldots, A_{m}\right)$.

Step 2: Create team of experts with $\mathrm{K}$ decision makers $D M_{k}(k=1,2, \ldots, K)$ and adopt set of criteria $C_{j}\left(C_{1}, C_{2}, \ldots, C_{n}\right)$.

Step 3: Create starting decision matrix using linguistic variables to evaluate ratings of criteria and alternatives concerning the adopted criteria. These linguistic variables are pre-defined and expressed in fuzzy numbers in range $[0,1]$ (Fig. 1).

Step 4: Defuzzificate starting decision matrix.

Step 5: Determine the best value $\left(f j^{*}\right)$ and the worst value $\left(f^{-}\right)$of all criteria ratings and compute the values $S_{i}$ and $R_{i}$ using Eq. (1) and Eq. (2).

Step 6: Compute the values $Q_{i}$ for alternatives using Eq. (3).

Step 7: Rank the alternatives using three different ranking lists in descend order by the values $S_{i}, R_{i}$ and $Q_{i}$.

Step 8: Determine the best ranked alternative by the measure $Q_{i}$ and propose it as a compromise solution if the following two conditions are satisfied [3]:

Acceptable $\quad$ Advantage: $\quad Q\left(A^{I}\right)-Q\left(A^{I I}\right) \geq$ $D Q, D Q=\min 0.25$

where: $A^{I}$ and $A^{I I}$ are alternatives ranked on the first and second positions in the set of micro location alternatives and $D Q$ is the threshold.

Acceptable Stability: The alternative $A^{I}$ has to be also the best ranked by $Q S$ or $Q R$.

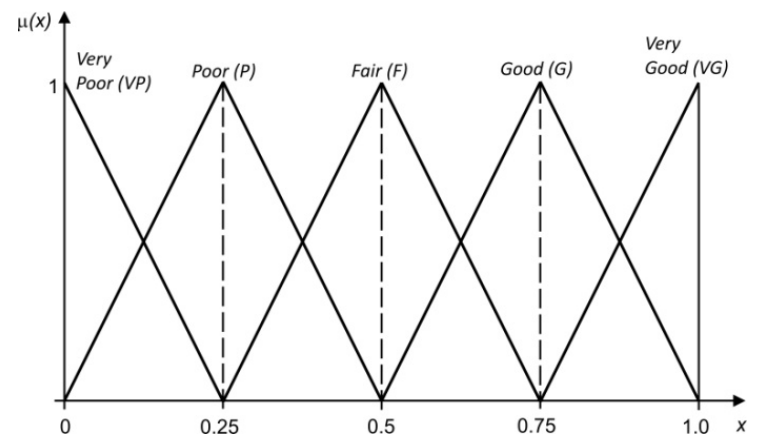




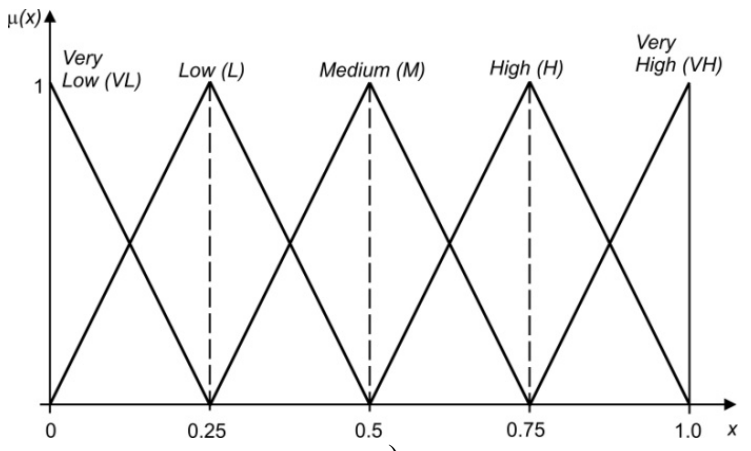

a)

Fig. 1 a) Linguistic variable of criteria weights

b) Linguistic variable of alternative ratings

\section{Illustrative example}

As a case study we present a several alternatives for locating rail-road transhipment facilities in the area of the rail freight yard in Vršac. The terminal will be located on an important national rail and road routes, and, also, international connection between Corridor IV and Corridor X, situated near river Danube. The intermodal terminal will be located on the outskirts of the city, near to the existing railway station Vršac. The initial framework for connecting intermodal terminal to the public railway network is based on the guidelines to retain existing location of Vršac railway station, as proposed in the Master Plan of Vršac and in the Development Program of Serbian Railways [7].

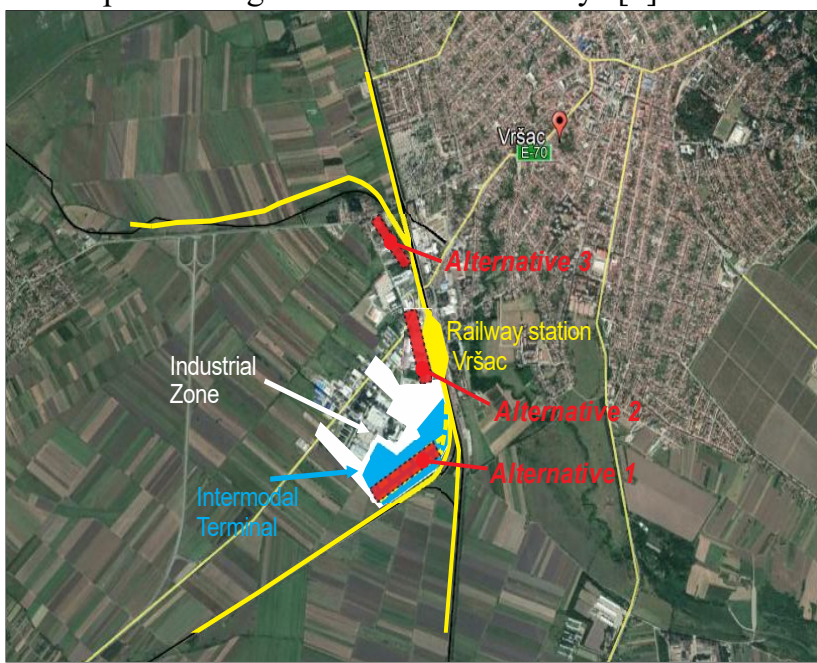

Fig. 2 Intermodal terminal in Vršac with alternatives for road-rail transhipment facilities

Three alternatives were considered as a potential location for road-rail transhipment facilities as presented of Figure 2:

- $\mathrm{A}_{1}$ - location of rail tracks within intermodal terminal and logistic centre;

- $\mathrm{A}_{2}$ - building new sidings parallel to existing station tracks in station Vršac;

- $\mathrm{A}_{3}$ - location of new sidings on the area next to the existing depot.

Team of three experts $\left(\mathrm{DO}_{1}, \mathrm{DO}_{2}\right.$ and $\left.\mathrm{DO}_{3}\right)$ in transport economics, railway infrastructure and operation is formed in the second step. Also, the list of criteria $\left(\mathrm{C}_{1}-\right.$ Investment and land acquisition costs, $\mathrm{C}_{2}$ - Efficiency and quality of rail operations, $\mathrm{C}_{3}$ Accessibility and quality of logistic services, $\mathrm{C}_{4}$ Availability of road connections, $\mathrm{C}_{5}$ - Availability of land for further development, $\mathrm{C}_{6}-$ Environmental restrictions) is adopted to evaluate proposed micro location alternatives.

In the third step, team of experts firstly weights set of criteria using linguistic variables with triangular fuzzy numbers (Fig. 1a). The membership functions of these linguistic variables are presented in Tab. 1 while the assigned weights are presented in Tab. 2 .

Table 1 Linguistic scale to evaluate the weight of the criteria

\begin{tabular}{|l|c|c|}
\hline \multicolumn{2}{|c|}{ Linguistic scale } & Fuzzy number \\
\hline \hline Very Low & VL & $(0,0,0.25)$ \\
\hline Low & L & $(0,0.25,0.5)$ \\
\hline Medium & M & $(0.25,0.5,0.75)$ \\
\hline High & H & $(0.5,0.75,1)$ \\
\hline Very High & VH & $(0.75,1,1)$ \\
\hline
\end{tabular}

Table 2 Linguistic weights of the criteria

\begin{tabular}{|c|c|c|c|}
\hline Criteria & DM1 & DM2 & DM3 \\
\hline \hline C1 & VH & H & VH \\
\hline C2 & M & VH & H \\
\hline C3 & M & L & H \\
\hline C4 & H & H & M \\
\hline C5 & M & M & H \\
\hline C6 & $\mathrm{H}$ & $\mathrm{M}$ & $\mathrm{L}$ \\
\hline
\end{tabular}

Secondly, the team of experts evaluates generated alternatives concerning the adopted set of criteria using linguistic variables with triangular fuzzy numbers (Fig. 1b). The membership functions of these linguistic variables are presented in Tab. 3. Tab. 4 presents assigned ratings by decision makers for each alternative concerning criterion. The starting decision matrix is formed combing linguistic variables from Tab. 2 and Tab. 4.

Table 3 Linguistic scale to evaluate the ratings of the criteria

\begin{tabular}{|l|c|c|}
\hline \multicolumn{2}{|c|}{ Linguistic scale } & Fuzzy number \\
\hline \hline Very Poor & VP & $(0,0,0.25)$ \\
\hline Poor & P & $(0,0.25,0.5)$ \\
\hline Fair & F & $(0.25,0.5,0.75)$ \\
\hline Good & G & $(0.5,0.75,1)$ \\
\hline Very Good & VG & $(0.75,1,1)$ \\
\hline
\end{tabular}

Table 4 Linguistic ratings of the alternatives

\begin{tabular}{|c|c|c|c|c|c|c|c|}
\hline & Alternatives & $\mathbf{C}_{\mathbf{1}}$ & $\mathbf{C}_{\mathbf{2}}$ & $\mathbf{C}_{\mathbf{3}}$ & $\mathbf{C}_{\mathbf{4}}$ & $\mathbf{C}_{\mathbf{5}}$ & $\mathbf{C}_{\mathbf{6}}$ \\
\hline \hline \multirow{3}{*}{$\mathbf{D M}_{1}$} & $\mathbf{A}_{\mathbf{1}}$ & $\mathrm{G}$ & $\mathrm{F}$ & $\mathrm{VG}$ & $\mathrm{F}$ & $\mathrm{G}$ & $\mathrm{VG}$ \\
\cline { 2 - 9 } & $\mathbf{A}_{\mathbf{2}}$ & $\mathrm{F}$ & $\mathrm{G}$ & $\mathrm{G}$ & $\mathrm{P}$ & $\mathrm{VP}$ & $\mathrm{P}$ \\
\cline { 2 - 9 } & $\mathbf{A}_{\mathbf{3}}$ & $\mathrm{VG}$ & $\mathrm{P}$ & $\mathrm{VP}$ & $\mathrm{VP}$ & $\mathrm{F}$ & $\mathrm{F}$ \\
\hline \multirow{3}{*}{$\mathbf{D M}_{2}$} & $\mathbf{A}_{\mathbf{1}}$ & $\mathrm{F}$ & $\mathrm{F}$ & $\mathrm{G}$ & $\mathrm{G}$ & $\mathrm{G}$ & $\mathrm{VG}$ \\
\cline { 2 - 9 } & $\mathbf{A}_{\mathbf{2}}$ & $\mathrm{P}$ & $\mathrm{VG}$ & $\mathrm{G}$ & $\mathrm{F}$ & $\mathrm{P}$ & $\mathrm{P}$ \\
\cline { 2 - 8 } & $\mathbf{A}_{\mathbf{3}}$ & $\mathrm{P}$ & $\mathrm{VP}$ & $\mathrm{VP}$ & $\mathrm{P}$ & $\mathrm{F}$ & $\mathrm{P}$ \\
\hline \multirow{3}{*}{$\mathbf{D M}_{3}$} & $\mathbf{A}_{\mathbf{1}}$ & $\mathrm{G}$ & $\mathrm{F}$ & $\mathrm{VG}$ & $\mathrm{G}$ & $\mathrm{G}$ & $\mathrm{G}$ \\
\cline { 2 - 9 } & $\mathbf{A}_{\mathbf{2}}$ & $\mathrm{F}$ & $\mathrm{G}$ & $\mathrm{G}$ & $\mathrm{F}$ & $\mathrm{P}$ & $\mathrm{P}$ \\
\cline { 2 - 8 } & $\mathbf{A}_{\mathbf{3}}$ & $\mathrm{VG}$ & $\mathrm{P}$ & $\mathrm{P}$ & $\mathrm{VP}$ & $\mathrm{F}$ & $\mathrm{F}$ \\
\hline
\end{tabular}


In the fourth step, the starting decision matrix is defuzzificated. In the fifth and sixed step, the best and worst values of all criteria ratings $\left(f_{j}^{*}\right.$ and $\left.f_{j}^{-}\right)$are computed. Thereafter, the values $S_{i}, R_{i}$ and $Q_{i}$ are calculated based on equations (2), (3) and (4). After obtaining values for $S_{i}, R_{i}$ and $Q_{i}$, ranking list is computed for each of these values. Based on these rank lists it is possible to determine a compromise solution. Rank list and values $S_{i}, R_{i}$ and $Q_{i}$ for each alternative are demonstrated in Tab. 5.

Table 5 Rank list of alternatives based on values $\mathbf{S}, \mathbf{R}$ and $\mathbf{Q}$

\begin{tabular}{|c|c|c|c|}
\hline \multirow{2}{*}{} & \multicolumn{3}{|c|}{ Alternatives } \\
\cline { 2 - 4 } $\mathbf{A}$ & 0.09 & 0.63 & 0.8 \\
\hline $\mathbf{R}$ & 0.09 & 0.22 & 0.18 \\
\hline $\mathbf{Q}$ & 0.0 & 0.88 & 0.85 \\
\hline
\end{tabular}

\begin{tabular}{|c|c|c|c|}
\hline \multirow{2}{*}{} & \multicolumn{3}{|c|}{ Alternatives } \\
\cline { 2 - 4 } & $\mathbf{1}$ & $\mathbf{2}$ & $\mathbf{3}$ \\
\hline $\mathbf{S}$ & $\mathrm{A}_{1}$ & $\mathrm{~A}_{2}$ & $\mathrm{~A}_{3}$ \\
\hline $\mathbf{R}$ & $\mathrm{A}_{1}$ & $\mathrm{~A}_{3}$ & $\mathrm{~A}_{2}$ \\
\hline $\mathbf{Q}$ & $\mathrm{A}_{1}$ & $\mathrm{~A}_{2}$ & $\mathrm{~A}_{3}$ \\
\hline
\end{tabular}

Results of multi-criteria evaluation using Fuzzy VIKTOR method and the rank of alternatives show that the alternative $A_{1}$ is the compromise solution due to the first position in the rank list and satisfaction of conditions:

\section{Acceptable Advantage:}

$$
Q\left(A_{3}\right)-Q\left(A_{1}\right)=0.85, D Q>0,25 \text { and }
$$

Acceptable Stability: the alternative $A_{1}$ is the first

ranked in the lists based on measures $S$ and $R$.

In addition, we consider the stability of ranking results considering changes in the values of the parameter $v$. The parameter $v$ plays important role in the ranking procedure and reflects a balance between two strategies: a maximum group utility and a minimum of individual regret of the opponent. Figure 3 shows priority ranking comparisons considering different values of the parameter $v$ from 0 to 1 . It shows that the best ranked alternative is the same in terms of both strategies and satisfies the condition of the acceptable advantage over the entire interval $v=[0,1]$ while some changes appear in ranking other alternatives. In terms of a minimum individual regret of the opponent ( $v$ equal or lower than 0.5$)$, the alternatives are in order $A_{1}, A_{3}, A_{2}$. When considering a maximum group utility to be more important ( $v$ equal or higher then 0.6), alternatives $\mathrm{A}_{2}$ and $\mathrm{A}_{3}$ switch ranking positions.

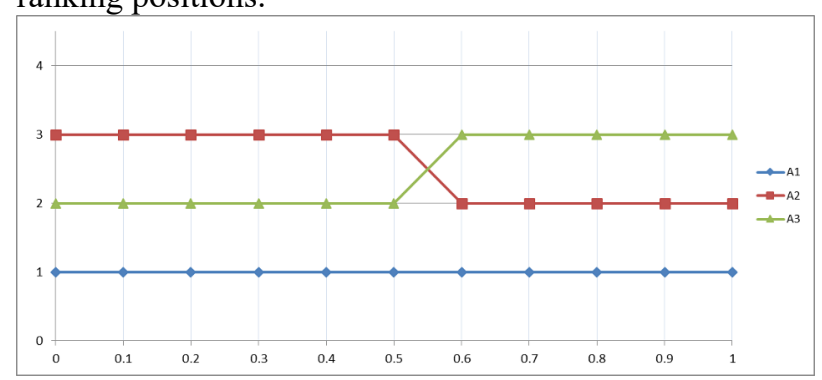

Fig. 3 Sensitivity analysis of the value $v$

\section{Conclusion}

The proposed MCDM model provides overall and systemic solution to the problem of selecting the most favourable micro location for the rail-road transhipment yard. In this model, proposed location alternatives are compared using different criteria (costs, rail operations, logistic services, road connections, spatial and environmental restrictions). We propose the use of fuzzy VIKOR method to evaluate location alternatives based on linguistic variables used to evaluate weights of criteria and alternatives concerning to the adopted set of criteria. These linguistic values are pre-defined and expressed in fuzzy numbers. The model extends the evaluation problem to a Group Decision Making (GDM) procedure. The final result of the multi-criteria decision-making analysis is the selection of the most suitable micro location. The most suitable location is the best solution from the set of defined alternatives in accordance with the adopted criteria. The result in the presented example shows that this model is practical and represents helpful tool for assisting decision makers in selecting the transhipment yard location that satisfy the often-conflicting criteria.

$\left(\mathrm{C}_{1}-\right.$ Investment and land acquisition costs, $\mathrm{C}_{2}-$ Efficiency and quality of rail operations, $\mathrm{C}_{3}-$ Accessibility and quality of logistic services, $\mathrm{C}_{4}-$ Availability of road connections, $\mathrm{C}_{5}$ - Availability of land for further development, $\mathrm{C}_{6}-$ Environmental restrictions) is adopted to evaluate proposed micro location alternatives.

This work was supported by the Slovak Research and Development Agency under the contract No. SK-SRB2016-0024. This work is supported by The Ministry of Education, Science and Technological Development of the Republic of Serbia, within the project No. 36012.

\section{References}

1. Belosević, M. Ivić, M. Kosijer, N. Pavlović, S. Aćimović 2nd Logistics International Conference, Belgrade, Serbia, 62-67. (2015).

2. I. Belosević, M. Ivić, M. Kosijer, N. Pavlović, S. Aćimović. Hrizons. 463-469. (2016).

3. S. Opricović, G.H. Tzeng: European Journal of Operational Research, 2(178): 514-529, (2007).

4. S. Opricović: Fuzzy Expert Systems with Applications, 10(38): 12983-12990, (2011).

5. I. Belosević, M. Kosijer, M. Ivić, N. European Transport Research Review 10:43. (2018) https://doi.org/10.1186/s12544-018-0318-4

6. M. Kosijer, M. Ivić, M. Marković, I. Belosević. Građevinar, 3(64): 195-205, (2012).

7. J. Masek, M. Kendra, J. Camaj, S. Milinković, S., Vesković, S.,. Transport Problems. 10 (Issue 4), 107-119 (2015) 